\title{
Awareness, knowledge and self-reported test rates regarding Hepatitis B in Turkish-Dutch: a survey
}

Ytje JJ van der Veen ${ }^{1,2^{*}}$, Hélène ACM Voeten ${ }^{1,2}$, Onno de Zwart $^{2}$, Jan Hendrik Richardus ${ }^{1,2}$

\begin{abstract}
Background: Hepatitis B virus infection is an important health problem in the Turkish community in the Netherlands. To prevent transmission and progression of the disease in this community, increased screening is necessary. This study aimed to determine 1) the levels of awareness and knowledge regarding hepatitis $B$, comparing these in tested and non-tested Turkish-Dutch in Rotterdam; 2) the self-reported hepatitis B test status in this population, and how this is related to demographic characteristics, knowledge and awareness.

Methods: We conducted a postal survey amongst first and second generation migrants, aged 16 - 40 years.

Results: The response rate was $30.2 \%$ ( $n=355$ respondents). Levels of awareness and knowledge regarding hepatitis B were low, as the majority of respondents (73\%) never thought about the disease and $58 \%$ of the respondents scored 5 or less out of ten knowledge items. Weighted analysis of self-reports showed a test rate of $15 \%$, and a vaccination rate of $3 \%$. Regression analysis showed that having been tested for hepatitis B was related to being married and higher levels of awareness and knowledge.

Conclusions: This study shows low levels of hepatitis B awareness and knowledge in the Turkish community in Rotterdam. Self-reported test rates are lower in people who are not currently married, and in those who have low levels of awareness and knowledge. Especially, knowledge about the consequences of hepatitis B, such as liver cancer, was lacking. Therefore, a health promotion intervention should foremost raise awareness, and increase knowledge on the seriousness of this disease.
\end{abstract}

\section{Background}

Hepatitis B virus (HBV) infection is one of the major infectious diseases in the world [1]. The endemic status of the Netherlands is classed as low, but population migration from high or medium endemic countries affects the HBV prevalence [2,3]. Each year, around 1,800 HBV infections, $79 \%$ of which are chronic, are reported in the Netherlands [4]. Chronic HBV infections cause $23 \%$ of all liver cancers in the Netherlands, and are an important problem in ethnic minority groups, such as the Turkish community [5,6]. While this community represents $8 \%$ of the total city population in Rotterdam, it accounts for $30 \%$ of reported chronic HBV infections [7]. Seventy percent of reported infections

\footnotetext{
* Correspondence: y.vanderveen@ggd.rotterdam.nl

'Erasmus MC, University Medical Center Rotterdam, Dept. of Public Health, Rotterdam, the Netherlands

Full list of author information is available at the end of the article
}

among Turks involve people aged between 16 and 40 . In this age-category, the mean incidence of reported HBV infections is 122 per 100,000 Turkish-Dutch individuals, much higher than the 35 infections per 100,000 persons reported in the total population of Rotterdam (Municipal Public Health Services Rotterdam-Rijnmond (MPHS), unpublished data, Rotterdam, 2007). However, these figures underestimate the population-prevalence: many chronic HBV-patients do not have disease symptoms, and are not reported. Population-based studies indicate a prevalence of chronic HBV of $0.2 \%$ in the general Dutch population, and a prevalence of 2.6 $4.8 \%$ in the Turkish-Dutch population [6,8-10].

Most reported patients with chronic HBV have acquired HBV from their mother at birth [4]. Later in life, however, transmission is mainly through sexual contact [11].
C Biomed Central

(c) 2010 van der Veen et al; licensee BioMed Central Ltd. This is an Open Access article distributed under the terms of the Creative Commons Attribution License (http://creativecommons.org/licenses/by/2.0), which permits unrestricted use, distribution, and reproduction in any medium, provided the original work is properly cited. 
HBV control now focuses both on pregnancy screening and on vaccinating risk groups, such as newborns from $\mathrm{HBV}$-infected mothers, children with parent(s) from an HBV-endemic area, and people with high-risk behaviour [11]. These programmes however, have not contributed to the health of the general adult Turkish-Dutch population, leaving a substantial part of this population both undetected and unprotected regarding HBV.

In the past decade, treatment possibilities of chronic HBV have improved [12]. In order to detect individuals eligible for treatment and to prevent horizontal transmission in sexually (pre-)active individuals, screening for HBV should be promoted specifically in the Turkish-Dutch population. Public health interventions should target those who are least likely to participate in screening. Studies in Asian-American migrant groups, have shown that a lower screening rate is related to demographic factors - such as younger age, lower level of education, poor language proficiency, lower socio-economic status, and not having a health insurance - and lower levels of knowledge and awareness regarding HBV [13-22].

This study is a first step in developing an intervention aimed at the promotion of HBV-screening in the Turkish-Dutch population in Rotterdam. In order to target this intervention adequately, the current study aimed to determine 1) the levels of awareness and knowledge regarding $\mathrm{HBV}$, comparing these in tested and nontested members of the Turkish-Dutch population in Rotterdam; 2) the self-reported HBV test status in this population, and how this is related to demographic characteristics. In the next phase, we will determine causal relationships between behavioural and cultural determinants and $\mathrm{HBV}$-screening behaviour.

\section{Methods}

A sample of 1176 inhabitants of Rotterdam was drawn from the municipal administration. Included were people born in Turkey (first-generation migrants (FGM)); and people born in the Netherlands, with FGM parents (second-generation migrants (SGM)). Stratification was done on the basis of gender, migrant generation, and 5 -year age group to ensure a minimum number of participants in each stratum. In order to over-sample strata in which a lower response was anticipated, we used response percentages reported for a health survey in the same population [23].

The questionnaires were translated and back-translated by two Turkish-Dutch translators. Inconsistencies in the translation and different understandings of concepts were discussed until consensus was reached between the translators.

One week after an announcement from the MPHS, asking for participation in the survey, FGM received a letter and questionnaire in both Turkish and Dutch language. SGM received the letter and questionnaire in Dutch only. Turkish-spoken support in filling out the questionnaire was available through telephone contact. Reminder packages consisting of a letter and questionnaire were sent to those who had not responded within three weeks. One week thereafter, all non-responders registered in the public telephone register were called and asked to respond. Furthermore, we stimulated participation by giving interviews on local radio stations, and by organising a lottery of gift vouchers among respondents.

Data-collection took place from March to May 2008. The Medical Ethical Review Board of Erasmus MC, University Medical Center Rotterdam, approved this study.

Development of the questionnaire (Additional file 1) was guided by focus group discussions in the Turkish community in Rotterdam [24]. The questionnaire contained the following sections:

Socio-demographic factors were sex, age, first- or second-generation migrant status, marital status, country of birth of partner, level of education (low-medium-high), socio-economic status (SES) of the residential area (categorized in low-mid/high SES), income situation, type of health insurance and Dutch language proficiency and use. Questions on the history of Hepatitis B testing and vaccination included test results and the persons' experience with HBV in family and friends. Awareness was measured through four separate items about the frequency of having thought about HBV in the past year. Answers could be given on a three-point scale 'never (1) - sometimes (2) - often (3)'. Knowledge was measured by ten statements, on which respondents could answer true, not true, or I don't know. Six statements on transmission and consequences were derived from a questionnaire by Taylor et al. [15]. We also formulated two statements on prevention. As focus group discussions in this population had indicated confusion in knowledge about hepatitis $A$ and $B$, the last two statements assessed this issue. The total individual knowledge score could range from $0-10$.

We also measured social-cognitive and socio-cultural determinants of hepatitis B screening but these will be described in a separate paper.

Because we used stratification in our sampling, we weighted all demographic characteristics, test rates, and awareness and knowledge scores by sex, age group and migrant generation, to be representative for the 16 to 40 year old Turkish-Dutch population in Rotterdam as per 1 January 2008. We compared tested and non-tested individuals regarding awareness and knowledge by using the chi-squared statistic. For this analysis, we dichotomized the awareness scores into low level (never thought about [the item] in the past year) versus high level (sometimes or often thought about [the item] in 
the past year), and we dichotomized the knowledge scores into 1 (correct answer) versus 0 (incorrect answer/'don't know'). We then used logistic regression analysis, adjusted for the stratification variables sex, age and migrant generation, to summarize the independent associations of demographic characteristics with having been tested for HBV. In the multivariate logistic regression analysis, we used stepwise backward selection of the variables which univariately showed a p-value $\leq$ 0.15 . Finally, a second regression model was built which included the levels of awareness and knowledge, next to the demographic variables. In this multivariate analysis, we summarized the overall awareness into low (never thought about any of the awareness items in the past 12 months) versus high (at least thought about one of the four awareness-items in the past 12 months). We summarized the overall knowledge into low (0-5 correct answers) versus high ( $>5$ correct answers).

\section{Results}

The response rate was $30.2 \%(\mathrm{n}=355)$. In the past 12 months, $27 \%$ of the respondents $(n=97)$ had thought at least once about one or more of the four awareness items (Table 1). This overall level of awareness differed between tested and non-tested individuals: $42 \%$ of tested people had some awareness, in contrast with $24 \%$ in the non-tested group $(\mathrm{p}<.01)$. Proportionately more tested than non-tested people had thought about the various awareness questions, except for the question about the risk of a family member contracting HBV. Both groups had hardly thought about this risk $(10 \%$ and $9 \%, \mathrm{p}=.8)$.

The first three knowledge items focussed on HBV transmission. The average proportion of respondents who answered these items correctly was $54 \%$ (Table 2). For the three items, which tested knowledge about the consequences of $\mathrm{HBV}$, the average proportion was $35 \%$; for the two items about the prevention of HBV it was $68 \%$. On average, $33 \%$ of respondents gave correct answers to the two statements about the difference between hepatitis A and B. Overall, the level of knowledge was higher in people who had been tested. The exceptions were the knowledge about the transmission of HBV during childbirth, which was about equally known by tested and non-tested $(62 \%$ vs. $53 \%, \mathrm{p}=.22)$, and the prevention of HBV by screening, which was known by $84 \%$ in both groups $(p=.8)$. The level of knowledge about hepatitis $\mathrm{A}$ and $\mathrm{B}$ vaccination was equal in both groups ( $64 \%$ vs. $52 \%, \mathrm{p}=.14$ ). Fifty eight percent of the respondents answered less than six items correctly. There were no significant differences between men and women regarding awareness and knowledge, although men tended to be less aware of HBV $(\mathrm{p}=.08)$. Awareness in FGM and SGM was equally low; the awareness of SGM men younger than 30 being the poorest. FGM appeared to have less knowledge than SGM ( $p=.06)$, with SGM women (21-30 year) having the highest level of knowledge. There were no significant differences in awareness and knowledge between the age groups, although the age group 26-30 years had slightly more knowledge with 55\% scoring 6 or more of the items correctly, compared to $42 \%$ in the total of all age groups.

Univariate logistic regression analysis of the level of awareness and knowledge with regard to having been tested for HBV, showed that relatively more people with some awareness (i.e. those who had at least thought about one of the four awareness-items in the past year) had been tested (OR $2.7(1.5-4.8, \mathrm{p}<.001)$ than people who had no awareness at all. It also showed that relatively more people with a knowledge-score of at least 6 out of 10, had been tested (OR 3.6 (2.0-6.6), p <.001) than people with a lower knowledge-score.

Although in the weighted analysis 52 people (14.7\%) reported having been tested for HBV, only 42 of them reported the test results. In $86 \%(36 / 42)$ no antibodies against HBV had been detected in the blood. Four people reported that the screening had shown the presence of anti-HBc (antibodies to HBV core antigen), indicating infection with the virus in the past resulting in immunity. Four out of the 42 people $(9.5 \%)$ reported to be carriers of HBV. Regarding vaccination, eleven respondents $(11 / 355,3 \%)$ were sure to have received full vaccination against $\mathrm{HBV}$ (i.e. 3 shots); while another $41(12 \%)$ had not received the full series or were not

Table 1 Level of awareness regarding Hepatitis B in the Turkish-Dutch population in Rotterdam (weighted analysis)

\begin{tabular}{|c|c|c|c|c|}
\hline & $\begin{array}{c}\text { total } \\
\mathrm{n}=355 \\
\%\end{array}$ & $\begin{array}{c}\text { tested } \\
\mathrm{n}=52 \\
\%\end{array}$ & $\begin{array}{c}\text { non-tested } \\
\mathrm{n}=303 \\
\%\end{array}$ & p-value \\
\hline \multicolumn{5}{|l|}{ Persons who in the past 12 months have at least sometimes thought about } \\
\hline the disease Hepatitis B & 20 & 32 & 18 & 0.01 \\
\hline the personal risk in contracting Hepatitis B & 17 & 29 & 15 & $<0.01$ \\
\hline the risk of a family member contracting Hepatitis B & 9 & 10 & 9 & 0.8 \\
\hline having a test for Hepatitis $B$ & 13 & 24 & 11 & 0.02 \\
\hline Overall (\% of respondents who have thought about at least one of the four items) & 27 & 42 & 24 & $<0.01$ \\
\hline
\end{tabular}


Table 2 Proportion of people with correct knowledge about Hepatitis B among the tested and non-tested TurkishDutch population in Rotterdam (weighted analysis)

\begin{tabular}{|c|c|c|c|c|}
\hline & $\begin{array}{l}\text { total } \\
\mathrm{n}=355 \\
\%\end{array}$ & $\begin{array}{l}\text { tested } \\
n=52 \\
\%\end{array}$ & $\begin{array}{l}\text { non-tested } \\
n=303 \\
\%\end{array}$ & p-value \\
\hline \multicolumn{5}{|l|}{ Transmission } \\
\hline Hepatitis B cannot be spread by someone that looks and feels healthy. & 54 & 68 & 51 & 0.03 \\
\hline Hepatitis B can be spread during childbirth. & 54 & 62 & 53 & 0.22 \\
\hline Hepatitis B can be spread during sexual intercourse. & 53 & 67 & 50 & 0.02 \\
\hline Average proportion for transmission & 54 & 66 & 51 & 0.02 \\
\hline \multicolumn{5}{|l|}{ Consequences of HBV } \\
\hline People with Hepatitis B can be infected for life. & 44 & 69 & 39 & $<0.001$ \\
\hline Hepatitis B can cause liver cancer. & 25 & 43 & 22 & $<0.001$ \\
\hline People can die from Hepatitis B. & 36 & 53 & 34 & $<0.01$ \\
\hline Average proportion for consequences & 35 & 55 & 32 & $<0.001$ \\
\hline \multicolumn{5}{|l|}{ Prevention } \\
\hline Infection with Hepatitis B can not be prevented. & 52 & 75 & 48 & $<0.001$ \\
\hline By being tested for Hepatitis B, one can find out whether one is infected. & 84 & 84 & 84 & 0.8 \\
\hline Average proportion for prevention & 68 & 79 & 66 & 0.001 \\
\hline \multicolumn{5}{|l|}{ Difference Hepatitis A (HAV) and HBV } \\
\hline Hepatitis A and B are transferred from one person to the other in the same way. & 13 & 20 & 12 & 0.15 \\
\hline Vaccination for both Hepatitis A and B are available. & 54 & 64 & 52 & 0.14 \\
\hline Average proportion for difference HAV and HBV & 33 & 41 & 32 & 0.16 \\
\hline Percentage of respondents with a high score (i.e. 6 or more correct answers) & 42 & 71 & 37 & $<0.001$ \\
\hline
\end{tabular}

sure about the completeness of the vaccination series. The majority of respondents had not been vaccinated (37\%) or did not know whether they had been vaccinated (48\%).

Univariate analysis showed that proportionately more respondents who knew family members or friends with HBV had been tested than those who did not (OR 3.4 (1.7 - 6.7), $\mathrm{p}<.001)$ (Table 3$)$. In the multivariate model which included the factors gender, age, migrant generation, marital status and knowing someone with HBV, this latter factor remained significantly related to having been tested (OR $3.4(1.7-6.7), \mathrm{p}<.001)$. When including the levels of awareness and knowledge in the multivariate analysis, being married (OR $2.4(1.1-5.2), \mathrm{p}<$ $.05)$, and higher levels of awareness (OR 2.3 (1.3 - 4.3, p $<.01)$ and knowledge (OR 3.8 (2.0-7.1, p < .001) remained significantly related to having been tested. In this second model, knowing someone with HBV was borderline significantly related to having been tested for $\operatorname{HBV}(\mathrm{p}=.06)$.

\section{Discussion and Conclusions}

This study shows that the level of awareness regarding HBV in the Turkish-Dutch population is low. While $\mathrm{HBV}$ is a serious health problem in this community, over $70 \%$ of respondents have never thought about it in the past year. Knowledge about transmission and prevention of $\mathrm{HBV}$ is moderate, while there is especially little knowledge about the serious consequences of HBV. In this study, low HBV test- and vaccination rates are reported (15\% and $3 \%$, respectively). Test rates are even lower in people who are not married, or have lower levels of awareness and knowledge.

This study is the first research into awareness and knowledge regarding $\mathrm{HBV}$ and $\mathrm{HBV}$-test rates in the Turkish community in the Netherlands, but it also has some limitations. Firstly, although we tried to stimulate response in various ways, the response rate was rather low (30.2\%). This may be an indication of a lack of interest for the subject of hepatitis B which may jeopardize future participation in the intervention. The low response rate may also cause selection bias. Nonresponse analysis shows that non-respondents differed from respondents only with regard to gender (proportion female was $44 \%$ among non-respondents versus $54 \%$ among respondents), and not to age, migration generation and socio-economic status. Furthermore, the reported percentage of $\mathrm{HBV}$ carriers in our study is 9.5\%, while we expected this to be between $2.6-4.8 \%$ $[6,8-10]$. This indicates that persons affected by HBV might have been more willing to respond, and that actual levels of awareness and knowledge in the population might be even lower than presented in this study. Secondly, information bias might have occurred, as in our questionnaire we gave away some information about testing and vaccination. This may have resulted in 
Table 3 Hepatitis B test-rates related to demographic factors in the Turkish-Dutch population in Rotterdam, the Netherlands $(n=355)$

\begin{tabular}{|c|c|c|c|c|c|c|c|}
\hline & & $\begin{array}{c}\text { total } \\
n=355\end{array}$ & $\begin{array}{l}\text { Tested }^{\mathrm{c}} \\
\mathrm{n}=52\end{array}$ & crude OR (univariate) & p-value & adjusted OR (multivariate) $^{\mathrm{e}}$ & p-value \\
\hline Total & & $100 \%$ & $14.7 \%$ & & & & \\
\hline \multirow[t]{2}{*}{ Sex } & female & $54 \%$ & $15 \%$ & $1.1(0.6-1.8)$ & 0.8 & $1.1(0.6-2.0)$ & 0.7 \\
\hline & male & $46 \%$ & $14 \%$ & ref & & & \\
\hline \multirow[t]{6}{*}{ Age group } & & & & & 0.13 & & 0.1 (overall) \\
\hline & $16-20$ & $19 \%$ & $11 \%$ & ref & & & \\
\hline & $21-25$ & $16 \%$ & $12 \%$ & $1.2(0.4-3.7)$ & 0.7 & $1.5(0.5-5.0)$ & 0.5 \\
\hline & $26-30$ & $20 \%$ & $21 \%$ & $1.9(0.7-5.1)$ & 0.2 & $2.3(0.8-6.7)$ & 0.1 \\
\hline & $31-35$ & $21 \%$ & $11 \%$ & $1.6(0.6-4.4)$ & 0.3 & $1.7(0.6-4.8)$ & 0.36 \\
\hline & $36-40$ & $25 \%$ & $21 \%$ & $2.9(1.2-7.3)$ & 0.02 & $3.4(1.3-7.4)$ & 0.02 \\
\hline \multirow[t]{2}{*}{ Migrant generation $^{a}$} & 1st generation & $49 \%$ & $16 \%$ & ref & & & \\
\hline & 2nd generation & $51 \%$ & $13 \%$ & $1.2(0.7-2.1)$ & 0.5 & $1.4(0.8-2.5)$ & 0.3 \\
\hline \multirow[t]{2}{*}{ Marital status } & married/living with partner & $59 \%$ & $19 \%$ & $1.8(0.9-3.8)^{d}$ & 0.10 & & \\
\hline & previously/never married & $41 \%$ & $9 \%$ & ref & & & \\
\hline \multirow{2}{*}{$\begin{array}{l}\text { Country of birth of } \\
\text { partner }^{\text {b }}\end{array}$} & not/low endemic & $29 \%$ & $19 \%$ & $1.3(0.6-2.7)^{d}$ & 0.6 & & \\
\hline & high endemic & $71 \%$ & $17 \%$ & ref & & & \\
\hline \multirow{2}{*}{$\begin{array}{l}\text { HBV in family or } \\
\text { friends }\end{array}$} & yes & $15 \%$ & $36 \%$ & $3.4(1.7-6.7)^{d}$ & $<0.001$ & $3.4(1.6-6.7)$ & $<0.001$ \\
\hline & no & $85 \%$ & $11 \%$ & ref & & & \\
\hline \multirow[t]{4}{*}{ Educational level } & & & & & 0.23 & & \\
\hline & low & $32 \%$ & $14 \%$ & $1.1(0.5-2.4)^{d}$ & 0.8 & & \\
\hline & medium & $42 \%$ & $13 \%$ & ref & & & \\
\hline & high & $26 \%$ & $16 \%$ & $1.9(0.9-3.8)^{d}$ & 0.08 & & \\
\hline \multirow[t]{2}{*}{ SES suburb } & low SES suburb & $63 \%$ & $15 \%$ & $1.3(0.7-2.3)^{d}$ & 0.4 & & \\
\hline & medium/high SES suburb & $37 \%$ & $15 \%$ & ref & & & \\
\hline \multirow[t]{5}{*}{ Income situation } & & & & & 0.3 & & \\
\hline & paid job & $66 \%$ & $13 \%$ & ref & & & \\
\hline & social security & $8 \%$ & $19 \%$ & $1.0(0.4-3.1)^{d}$ & 0.9 & & \\
\hline & fulltime housework & $13 \%$ & $26 \%$ & $2.4(1.0-6.0)^{d}$ & 0.05 & & \\
\hline & student & $14 \%$ & $10 \%$ & $0.9(0.2-3.2)^{d}$ & 0.9 & & \\
\hline \multirow[t]{2}{*}{ Health insurance } & basic health insurance & $40 \%$ & $13 \%$ & ref & & & \\
\hline & basic + supplementary & $60 \%$ & $16 \%$ & $1.4(0.7-2.7)^{d}$ & 0.3 & & \\
\hline \multirow{2}{*}{$\begin{array}{l}\text { Dutch language } \\
\text { orientation } \\
\text { (proficiency and } \\
\text { use) }\end{array}$} & low level & $47 \%$ & $17 \%$ & ref & & & \\
\hline & high level & $53 \%$ & $13 \%$ & $1.3(0.7-2.5)^{d}$ & 0.5 & & \\
\hline
\end{tabular}

a 1st generation migrant i.e. person born in Turkey. 2nd generation migrant i.e. person born in the Netherlands, with at least one parent born abroad.

${ }^{b} \mathrm{n}=233$

c weighted analysis to correct for the stratification variables sex, age group and migrant generation

d adjusted for the stratification variables sex, age group and migrant generation

e the stratification variables sex, age group and migrant generation were retained in the final model

higher knowledge-scores on the prevention items. Thirdly, self-reports of screening and vaccination may be affected by inaccurate recall or desirability bias. Fourthly, we cannot assume causality between the factors on the one hand and having been tested on the other, because of the cross-sectional research design. Last, it is not likely that multiple testing has biased the conclusions as we found a considerable number of significant differences between the groups, with p-values below 0.001 .

We found low levels of knowledge regarding the consequences of HBV. Studies in Asian migrants in the USA found higher levels of HBV knowledge [25]. One possible explanation is that $\mathrm{HBV}$ is an even more prevalent health problem in Asian populations, than in the Turkish population. Another is that knowledge may 
have been improved by health education activities in the country of origin or in the host country [19]. As far as we know, this has not been the case for Turkish migrants coming to the Netherlands. These health education activities may also have influenced the test rates amongst Asian migrants in the USA (range 8 - 68\%) $[15,16,18,19,25-27]$, which were considerably higher than the test rate we found amongst Turkish Dutch (14.7\%).

Since 1989, national policy has prescribed HBVscreening for pregnant women. In our study, about $25 \%$ of the married females reported to have been tested. This proportion appears to be low in view of the fact that, based on demographic trend information in migrant women in the Netherlands, we estimate that in reality about $50 \%$ of all married females may have been tested during pregnancy $[28,29]$. This would result in a total test rate of $22 \%$, instead of the reported $15 \%$. The women who underreported screening, are likely women who tested negative for HBV and are susceptible to the virus. As the aim of our intervention is both detecting $\mathrm{HBV}$ and protecting against $\mathrm{HBV}$, we also target our intervention to these women in order to provide them with adequate preventive measures. Last, it is likely that screened women who appeared to be carriers are aware of having been tested, and therefore the underreporting does not affect the carrier rate.

Current screening guidelines also include source and contact tracing, which means that invitations for HBVscreening are extended to plausible source(s) and contacts of a notified HBV-carrier. This may explain the results of the regression analyses, which showed that the factors 'being married' and 'knowing a family member or friend with HBV' were (borderline) related to having been screened. The first time most of the TurkishDutch women will be tested for HBV is during pregnancy; which seldom occurs before marriage [30]. The fact that knowing someone with $\mathrm{HBV}$ is related to previous HBV-testing has been shown in other studies [16] as well as in our own. This may be due to HBV-affected family members or friends who are prompted to be tested themselves, or to the source and contact tracing.

Several studies found an association between higher age and having been tested [19,31]. Although in our study we found a tendency that older people were more often tested, this relation was not significant. While other studies also found that the level of education, language proficiency, and level of health insurance were associated with previous testing, our findings did not confirm this. Almost everyone in our study had a health insurance, and this factor was not associated with having been screened. It is suggested that in areas with high levels of health-care coverage, the influence of being insured has less effect on actually being screened [26].
This might also be valid for the level of education, which was high in our study.

This study shows that the Turkish population in Rotterdam has low levels of awareness and knowledge regarding $\mathrm{HBV}$, and low rates of HBV-testing and -vaccination. While the national HBV-screening policy in the Netherlands covers mainly pregnant women and their contacts, the risk of HBV is present in the whole Turkish-Dutch population. In order to prevent HBVtransmission in adults, it would be useful to test people before they become sexually active. The findings in the present study show that the development of a health promotion intervention regarding $\mathrm{HBV}$ should raise awareness about the risk of HBV in this population, and particularly address the serious consequences of $\mathrm{HBV}$.

\section{Additional material}

Additional file 1: Questionnaire on hepatitis B, testing and vaccination in the Turkish community in Rotterdam. Questionnaire on hepatitis B, testing and vaccination in the Turkish community in Rotterdam, including demographic items, questions on awareness and knowledge, and the history of testing and vaccination.

\section{Acknowledgements}

This study was funded by ZonMW, the Netherlands organisation for health research and development and was conducted within the Huisman Research Centre for Infectious Diseases and Public Health and CEPHIR, Centre for Effective Public Health in the larger Rotterdam area.

\section{Author details}

${ }^{1}$ Erasmus MC, University Medical Center Rotterdam, Dept. of Public Health, Rotterdam, the Netherlands. ${ }^{2}$ Municipal Public Health Service GGD Rotterdam-Rijnmond, Rotterdam, the Netherlands.

\section{Authors' contributions}

$\mathrm{OZ}$ and JHR and made substantial contributions to the conception and design of this study and revised the manuscript critically. $W$ organised the survey, analysed the data, and drafted the manuscript. YV and HV were involved in data-interpretation and in revising the manuscript. All authors read and approved the final manuscript.

\section{Competing interests}

The authors declare that they have no competing interests.

Received: 3 May 2010 Accepted: 24 August 2010

Published: 24 August 2010

\section{References}

1. Hepatitis B. [http://www.who.int/mediacentre/factsheets/fs204/en/].

2. Hahne SJ, Veldhuijzen IK, Smits LJ, Nagelkerke N, van de Laar MJ: Hepatitis $B$ virus transmission in The Netherlands: a population-based, hierarchical case-control study in a very low-incidence country. Epidemiol Infect 2008, 136(2):184-195.

3. Zuckerman J, van Hattum J, Cafferkey M, Gjorup I, Hoel T, Rummukainen ML, Weiland $\mathrm{O}$ : Should hepatitis $B$ vaccination be introduced into childhood immunisation programmes in northern Europe? Lancet Infect Dis 2007, 7(6):410-419.

4. Koedijk FD, op de Coul EL, Boot HJ, van de Laar MJ: Hepatitis B surveillance in the Netherlands, 2002-2005: acute infection is mainly via sexual contact while chronic infection is via vertical transmission 
through mothers from endemic regions. Ned Tijdschr Geneeskd 2007, 151(43):2389-2394.

5. van Lier EA, Rahamat-Langendoen JC, Van Vliet JA: Staat van Infectieziekten in Nederland 2006.Edited by: RIVM. Bilthoven: National Institute of Public Health and the Environment; 2007:36.

6. van Marrewijk CJ, Veldhuijzen IK, Conyn-van Spaendonck MA, Kooy H, van den Hof S, Dorigo-Zetsma JW: Prevalence of hepatitis B viral markers in the Dutch population: a population-based serosurveillance study (Pienter project). Bilthoven: National Institute of Public Health and the Environment 1999.

7. Mostert MC, Richardus JH, de Man RA: Evaluation of the Rotterdam guideline for referral in case of chronic hepatitis B: improvement possible via a shortening of the referral chain and better distribution of information. Ned Tijdschr Geneeskd 2003, 147(4):159-163.

8. van Steenbergen JE, Leentvaar-Kuijpers A, Baayen D, Dukers HT, van Doornum GJ, van den Hoek JA, Coutinho RA: Evaluation of the hepatitis B antenatal screening and neonatal immunization program in Amsterdam, 1993-1998. Vaccine 2001, 20(1-2):7-11

9. Marschall T, Kretzschmar M, Mangen M-JJ, Schalm S: High impact of migration on the prevalence of chronic hepatitis $B$ in the Netherlands. Eur J Gastroenterol Hepatol 2008, 20(12):1214-25.

10. Baaten GG, Sonder GJ, Dukers NH, Coutinho RA, Van den Hoek JA: Population-based study on the seroprevalence of hepatitis A, B, and C virus infection in Amsterdam, 2004. J Med Virol 2007, 79(12):1802-1810.

11. Health Council of the Netherlands: Universal vaccination against Hepatitis B.Edited by: Netherlands HCot. The Hague: Health Council of the Netherlands; 2001:

12. Lok AS, MCMahon BJ: Chronic hepatitis B. Hepatology 2007, 45(2):507-539.

13. Thompson MJ, Taylor VM, Yasui Y, Hislop TG, Jackson JC, Kuniyuki A, Teh C: Hepatitis B knowledge and practices among Chinese Canadian women in Vancouver, British Columbia. Can J Public Health 2003, 94(4):281-286.

14. Thompson MJ, Taylor VM, Jackson JC, Yasui Y, Kuniyuki A, Tu SP, Hislop TG: Hepatitis B knowledge and practices among Chinese American women in Seattle, Washington. J Cancer Educ 2002, 17(4):222-226.

15. Taylor VM, Yasui Y, Burke N, Nguyen T, Chen A, Acorda E, Choe JH, Jackson JC: Hepatitis B testing among Vietnamese American men. Cancer Detect Prev 2004, 28(3):170-177.

16. Taylor VM, Yasui Y, Burke N, Choe JH, Acorda E, Jackson JC: Hepatitis B knowledge and testing among Vietnamese-American women. Ethn Dis 2005, 15(4):761-767.

17. Taylor VM, Tu SP, Woodall E, Acorda E, Chen H, Choe J, Li L, Yasui Y, Hislop TG: Hepatitis B knowledge and practices among Chinese immigrants to the United States. Asian Pac J Cancer Prev 2006, 7(2):313-317.

18. Taylor VM, Choe JH, Yasui Y, Li L, Burke N, Jackson JC: Hepatitis B awareness, testing, and knowledge among Vietnamese American men and women. J Community Health 2005, 30(6):477-490.

19. Choe JH, Taylor VM, Yasui Y, Burke N, Nguyen T, Acorda E, Jackson JC Health care access and sociodemographic factors associated with hepatitis B testing in Vietnamese American men. J Immigr Minor Health 2006, 8(3):193-201.

20. Choe JH, Chan N, Do HH, Woodall E, Lim E, Taylor VM: Hepatitis B and liver cancer beliefs among Korean immigrants in Western Washington. Cancer 2005, 104(12 Suppl):2955-2958.

21. Chen H, Tu SP, Teh CZ, Yip MP, Choe JH, Hislop TG, Taylor VM, Thompson B: Lay beliefs about hepatitis among North American Chinese: implications for hepatitis prevention. J Community Health 2006, 31(2):94-112.

22. Hislop TG, Teh C, Low A, Li L, Tu SP, Yasui Y, Taylor VM: Hepatitis B knowledge, testing and vaccination levels in Chinese immigrants to British Columbia, Canada. Can J Public Health 2007, 98(2):125-129.

23. Van Buren $L P$, Joosten-van Zwanenburg E: Health survey amongst Turks and Moroccans aged 16-84 in Rotterdam in 2003/2004; study into the effect of research method on respons and representativity and information about health, well-being, life-style and health care use. Rotterdam: Municipal Public Health Services 2007, 79

24. van der Veen YJJ, de Zwart O, Voeten HA, Mackenbach JP, Richardus JH: Hepatitis B screening in the Turkish-Dutch population in Rotterdam, the Netherlands; qualitative assessment of socio-cultural determinants. BMC Public Health 2009, 9:328.
25. Taylor VM, Jackson JC, Chan N, Kuniyuki A, Yasui Y: Hepatitis B knowledge and practices among Cambodian American women in Seattle, Washington. J Community Health 2002, 27(3):151-163.

26. Coronado GD, Taylor VM, Tu SP, Yasui Y, Acorda E, Woodall E, Yip MP, Li L, Hislop TG: Correlates of hepatitis B testing among Chinese Americans. J Community Health 2007, 32(6):379-390.

27. Ma GX, Shive SE, Fang CY, Feng Z, Parameswaran L, Pham A, Khanh C: Knowledge, attitudes, and behaviors of hepatitis $B$ screening and vaccination and liver cancer risks among Vietnamese Americans. $J$ Health Care Poor Underserved 2007, 18(1):62-73.

28. De bevolkingsontwikkeling in een notendop (A note on Population changes). [http://www.nidi.knaw.nl/web/html/public/demos/dm03086.html].

29. Garssen J, Nicolaas H: Recente trends in de vruchtbaarheid van nietwesterse allochtone vrouwen. (Recent trends in fertility in non-western migrant women.). Bevolkingstrends (Demographic trends) 2006, , 54: 15-31.

30. Central Buro for Statistics $t N$ : Decreasing numbers of allochthonous teenage mothers. 2009.

31. Cheung J, Lee TK, Teh CZ, Wang CY, Kwan WC, Yoshida EM: Cross-sectional study of hepatitis B awareness among Chinese and Southeast Asian Canadians in the Vancouver-Richmond community. Can J Gastroenterol 2005, 19(4):245-249.

\section{Pre-publication history}

The pre-publication history for this paper can be accessed here: http://www.biomedcentral.com/1471-2458/10/512/prepub

\section{doi:10.1186/1471-2458-10-512}

Cite this article as: van der Veen et al: Awareness, knowledge and selfreported test rates regarding Hepatitis B in Turkish-Dutch: a survey. BMC Public Health 2010 10:512.

\section{Submit your next manuscript to BioMed Central and take full advantage of:}

- Convenient online submission

- Thorough peer review

- No space constraints or color figure charges

- Immediate publication on acceptance

- Inclusion in PubMed, CAS, Scopus and Google Scholar

- Research which is freely available for redistribution

Submit your manuscript at www.biomedcentral.com/submit
C Biomed Central 